\title{
IMPROVEMENT OF ALCOHOLIC BEVERAGES TECHNOLOGY FOR RESTAURANT BUSINESS
}

\author{
Kuzmin O. V., Mishurovskyi A. S.
}

\section{INTRODUCTION}

Today, vegetable raw materials are increasingly used in the development of alcoholic beverages ${ }^{1}$. Herbal beverages commonly consumed worldwide contain different chemical substances that display a broad spectrum of biological activities. They have gained growing interest among scientists and consumers due to their antioxidant properties and fragrance ${ }^{2}$. The ability of plant phenolics to act as free radical scavengers has led to increased interest in their ability to act as antioxidants ${ }^{3}$. Beverages are rich sources of natural bioactive compounds such as carotenoids, phenolic acids, flavonoids, coumarins, alkaloids, polyacetylenes, saponins and terpenoids, among others ${ }^{4}$.

${ }^{1}$ Andreou V., Strati I.F., Fotakis C., Liouni M., Sinanoglou V.J. Herbal distillates: A new era of grape marc distillates with enriched antioxidant profile. Food Chemistry. 2018. 253. P. 171-178; Chandrasekara A., Shahidi F. Herbal beverages: Bioactive compounds and their role in disease risk reduction - A review. Journal of Traditional and Complementary Medicine. 2018. 8 (4). P. 451-458; Iannitti T., Palmieri B. Antioxidant therapy effectiveness: an up to date. European Review for Medical and Pharmacological Sciences. 2009. 13. P. 245-278; Halliwell B., Gutteridge J.M.C. The antioxidants of human extracellular fluids. Archives of Biochemistry and Biophysics. 1990. 280. P. 1-8; Kawa-Rygielska J., Adamenko K., Kucharska A.Z., Szatkowska K. Fruit and herbal meads - Chemical composition and antioxidant properties. Food Chemistry. 2019. 283. P. 19-27; Fotakis C., Tsigrimani D., Tsiaka T., Lantzouraki D.Z., Zoumpoulakis P. Metabolic and antioxidant profiles of herbal infusions and decoctions. Food Chemistry. 2016. 211. P. 963-971.

${ }^{2}$ Pyrzynska K., Sentkowska A. 5: Herbal Beverages as a Source of Antioxidant Phenolics. Natural Beverages. 2019. P. 125-142.

${ }^{3}$ Keating L., Hayes J., Moane S., Lehane M., Furey A. The effect of simulated gastrointestinal conditions on the antioxidant activity of herbal preparations made from native Irish hawthorn. Journal of Herbal Medicine. 4(3). 2014. P. 127-133; Oh J., Jo H., Cho A.R., Kim S.J., Han J. Antioxidant and antimicrobial activities of various leafy herbal teas. Food Control. 2013. 31(2). P. 403-409; Herrera T., Aguilera Y., Rebollo-Hernanz M., Bravo E., Martín-Cabrejas M.A. Teas and herbal infusions as sources of melatonin and other bioactive non-nutrient components. LWT. 2018. 89. P. 65-73; Humia B.V., Santos K.S., Schneider J.K., Leal I.L., Padilha F.F. Physicochemical and sensory profile of Beauregard sweet potato beer. Food Chemistry. 2020. 312.

${ }^{4}$ Chandrasekara A., Shahidi F. Herbal beverages: Bioactive compounds and their role in disease risk reduction - A review. Journal of Traditional and Complementary Medicine. 2018. 8 (4). P. 451-458; Keating L., Hayes J., Moane S., Lehane M., Furey A. 
A wealth of available scientific evidence demonstrates that natural bioactive compounds render a number of diversified biological effects, such as antioxidant, antibacterial, antiviral, antiinflammatory, antiallergic, antithrombotic and vasodilatory actions, as well as antimutagenicity, anticarcinogenicity, antiaging effects ${ }^{5}$. These herbal teas are claimed to be antistress, immunomodulator, anti-aging, anti-inflammatory, appetizer, stimulant, blood purifier, energizer, antidepressant, antidiabetic, rejuvenative, analgesic, antiviral, nervine, diuretic, antihypertensive and memory enhancer ${ }^{6}$. Herbal antidepressants have been used to treat major depressive disorder, and there has been great advances in the understanding of the ability of these herbs to improve cognitive deficit linked to brain injury and various diseases including depression, Alzheimer disease, diabetes and age-related disorders ${ }^{7}$.

Excessive generation of reactive oxygen species (ROS) in the body causes oxidative stress, an injurious process leading to the oxidation of biomolecules such as proteins, lipids, carbohydrates and DNA. Oxidative stress is well known for its pivotal role in the etiology of several noncommunicable diseases (NCDs) such as cardiovascular diseases, arthritis, type 2 diabetes, different types of cancer, autoimmune diseases and neurodegenerative disorders, among others ${ }^{8,9}$.

The effect of simulated gastro-intestinal conditions on the antioxidant activity of herbal preparations made from native Irish hawthorn. Journal of Herbal Medicine. 4(3). 2014. P. 127-133; Oh J., Jo H., Cho A.R., Kim S.J., Han J. Antioxidant and antimicrobial activities of various leafy herbal teas. Food Control. 2013. 31(2). P. 403-409; Kuzmin O., Kovalchuk Y., Velychko V., Romanchenko N. Improvement technologies of aqueousalcoholic infusions for the production of syrups. Ukrainian Journal of Food Science. 2016. 4 (2). P. 258-275; Ruiz-Ruiz J.C., Aldana G.C.E, Cruz A.I.C., Segura-Campos M.R. 9: Antioxidant Activity of Polyphenols Extracted From Hop Used in Craft Beer. Biotechnological Progress and Beverage Consumption. 2020. P. 283-310; Naithani V., Nair S., Kakkar P. Decline in antioxidant capacity of Indian herbal teas during storage and its relation to phenolic content. Food Research International. 2006.39 (2). P. 176-181.

${ }^{5}$ Chandrasekara A., Shahidi F. Herbal beverages: Bioactive compounds and their role in disease risk reduction - A review. Journal of Traditional and Complementary Medicine. 2018.8 (4). P. 451-458.

${ }^{6}$ Naithani V., Nair S., Kakkar P. Decline in antioxidant capacity of Indian herbal teas during storage and its relation to phenolic content. Food Research International. 2006. 39(2). P. 176-181.

${ }^{7}$ Oh J., Jo H., Cho A.R., Kim S.J., Han J. Antioxidant and antimicrobial activities of various leafy herbal teas. Food Control. 2013. 31(2). P. 403-409.

${ }^{8}$ Chandrasekara A., Shahidi F. Herbal beverages: Bioactive compounds and their role in disease risk reduction - A review. Journal of Traditional and Complementary Medicine. 2018.8 (4). P. 451-458.

${ }^{9}$ Kuzmin O.V., Rudyi V.V. Prospects for the use of alcohol infusions in alcoholic beverage technologies for restaurants. Modern engineering research: topical problems, challenges and modernity : collective monograph. Riga : Izdevnieciba "Baltija Publishing", 2020. P. 211-230. 
The human body has endogenous antioxidant defense mechanisms those act simultaneously against ROS. These include enzymes (catalase, superoxide dismutase, glutathione reductase, glutathione peroxidase), low-molecularweight antioxidants (uric acid, glutathione, albumin, protein-SH groups, bilirubin) and certain vitamins (ascorbic acid, $\alpha$-tocopherol) as well as carotenoids. However, external sources of antioxidants are needed to prevent oxidative damage in the human body once internal antioxidant defense systems are challenged by over exposure to free radicals and other $\operatorname{ROS}^{10,11}$.

Currently, the market of alcoholic beverages in Ukraine is quite saturated with high-quality alcoholic beverages, the production and consumption of which in the country are growing steadily ${ }^{12}$. A large number of new varieties of multicomponent alcoholic beverages appear on the consumer market. They contain compounds that can change the biological activity of ethyl alcohol.

Modern consumers are faced with a difficult choice. The consumer pays attention not only to the appearance and taste characteristics of alcoholic beverages ${ }^{13,14}$. The consumer attaches special importance to the consequences associated with alcohol consumption ${ }^{15}$. Therefore, the creation

${ }^{10}$ Chandrasekara A., Shahidi F. Herbal beverages: Bioactive compounds and their role in disease risk reduction - A review. Journal of Traditional and Complementary Medicine. 2018.8 (4). P. 451-458.

${ }^{11}$ Halliwell B., Gutteridge J.M.C. The antioxidants of human extracellular fluids. Archives of Biochemistry and Biophysics. 1990. 280. P. 1-8.

${ }^{12}$ Kuzmin O.V., Rudyi V.V. Prospects for the use of alcohol infusions in alcoholic beverage technologies for restaurants. Modern engineering research: topical problems, challenges and modernity : collective monograph. Riga : Izdevnieciba "Baltija Publishing", 2020. - P. 211-230; Kuzmin O., Zubkova V., Shendrik T., Korenets Y., Kuzmin A., Bilenkyi P. Internal mechanisms for establishment of the equilibrium state of water-alcohol mixtures in vodka technology. Ukrainian Food Journal. 2018. 7 (4). P. 655-670; Kuzmin O., Suikov S., Koretska I., Matiyashchuk O., Poliovyk V. Identification of equilibrium state of hydroxyl protons in vodkas by ${ }^{1} \mathrm{H}$ NMR spectroscopy. Ukrainian Food Journal. 2017. 6(2). P. 314-336.

${ }^{13}$ Grunert K.G., Hieke S., Juhl H.J. Consumer wants and use of ingredient and nutrition information for alcoholic drinks: A cross-cultural study in six EU countries. Food Quality and Preference. 2018. 63. P. 107-118.

${ }_{14}$ Buglass A.J., Caven-Quantrill D.J. 16: Applications of natural ingredients in alcoholic drinks. Natural Food Additives, Ingredients and Flavourings. 2012. P. 358-416.

${ }^{15}$ Grunert K.G., Hieke S., Juhl H.J. Consumer wants and use of ingredient and nutrition information for alcoholic drinks: A cross-cultural study in six EU countries. Food Quality and Preference. 2018. 63. P. 107-118; Humia B.V., Santos K.S., Schneider J.K., Leal I.L., Padilha F.F. Physicochemical and sensory profile of Beauregard sweet potato beer. Food Chemistry. 2020. 312; Imark C., Kneubühl M., Bodmer S. Occurrence and activity of natural antioxidants in herbal spirits. Innovative Food Science \& Emerging Technologies. 2000. 1 (4). P. 239-243; Stern S.A., Terry-McElrath Y.M., Patrick M.E. Beverage-specific patterns of 5+ alcoholic drink consumption by young adults in the U.S. Addictive Behaviors. 2017. 65. P. 19-24. 
of alcoholic beverages, which to a lesser extent have a destructive effect on the body, is initiated by marketing and technological services of manufacturers to satisfy the desires of the buyer ${ }^{16}$.

A wide range of alcoholic beverages is based on the use of various vegetable raw materials ${ }^{17}$, from which semi-finished products are prepared aromatic alcohols, infusions, spirits, juices, etc. On the one hand, it opens up almost unlimited opportunities for the formation of taste, aroma, color of alcoholic beverages. On the other hand, there are difficulties with determining and standardizing the chemical composition, ensuring constant and predictable quality characteristics of alcoholic beverages.

Some herbal beverages are prepared from a single ingredient, however, they are often combined in mixtures in order to enhance their pharmacological effects. Thus, synergistic, additive, or antagonistic effects may be found in the antioxidant activity of mixtures of the popular herbs ${ }^{18}$.

To date, the antioxidant characteristics of all prescription components, food impurities, biologically active substances and their combinations have been insufficiently studied in alcoholic beverages. The mechanisms of their interaction with rectified ethyl alcohol, the effect of these substances and their combinations on the level of toxicity of alcoholic beverages require separate studies. Some components have the potential to increase the chronic toxicity of ethanol.

Alcoholic cocktails are one of the most relevant drinks in the world almost every restaurant has several types of alcoholic cocktails - some of them are ordered before meals to improve appetite, others - separately without meals to enjoy the bright «colors» of flavors. Also, with reasonable consumption of cocktails in acceptable doses, they have such useful properties as: stabilization of the state in hypertension; balancing the amount of glucose in the blood; adjustment of the digestive system; improving blood flow.

Also, alcoholic beverages, which are part of alcoholic cocktails, help prevent: stress; impaired brain activity; colds; osteoporosis; lymphoma; kidney tumors; angina pectoris; hypertension; type 2 diabetes; heart attacks; stroke.

In Ukraine, as well as around the world, there are alcoholic cocktails in various forms - from foreign originals to completely new species, developed

${ }^{16}$ Grunert K.G., Hieke S., Juhl H.J. Consumer wants and use of ingredient and nutrition information for alcoholic drinks: A cross-cultural study in six EU countries. Food Quality and Preference. 2018. 63. P. 107-118.

17 Buglass A.J., Caven-Quantrill D.J. 16: Applications of natural ingredients in alcoholic drinks. Natural Food Additives, Ingredients and Flavourings. 2012. P. 358-416.

${ }_{18}$ Pyrzynska K., Sentkowska A. 5: Herbal Beverages as a Source of Antioxidant Phenolics. Natural Beverages. 2019. P. 125-142. 
in Ukraine. Their wide range and variety is associated with the ability to mix alcohol with a large number of ingredients and also in different proportions to obtain flavors that are completely different from each other and their various useful properties.

But among all the useful properties, the main one will be the change of redox reactions. Redox reactions affect the ratio of the amount of energy to maintain homeostasis (relative dynamic constancy of the composition and properties of the internal environment and the stability of the basic physiological functions of the body) and ensures the viability of any organism. The value of this rate depends on the ratio and concentrations of oxidized and reduced substances in the body, including substances that come with food and beverages, so one of the main factors regulating the parameters of redox reactions is the redox potential.

In the production of cocktails, one of the possibilities of influencing the antioxidant properties of the product is the extraction of vegetable raw materials into alcohol-containing raw materials and the replacement of alcoholic beverages in the recipe.

This can improve organoleptic characteristics and increase the antioxidant properties of alcoholic cocktails. You can get such raw materials by infusing vegetable raw materials in a water-alcohol mixture.

These circumstances determine the relevance of the topic of scientific work, which is to develop water-alcohol infusions from vegetable raw materials in the technology of alcoholic cocktails in restaurants. The creation of alcoholic cocktails with low toxicity, due to the introduction of herbal infusions with antioxidant properties, allows restaurants to create new products that differentiate them from competitors, creating a favorable image of the institution, which protects consumers from the negative effects of alcohol.

The purpose of the work is to develop the scientific basis of antioxidant activity of water-alcohol infusions from plant raw materials and to identify the most promising plants as sources of natural antioxidants in the creation of alcoholic cocktails in restaurants.

When achieving this goal, it is necessary to solve the following problems:

- theoretically substantiate the prospects for the use of water-alcohol infusions from vegetable raw materials in the production of alcoholic cocktails;

- to establish the value of the regenerative capacity of water-alcohol infusions from plant raw materials;

- to conduct organoleptic evaluation of water-alcohol infusions and determine their prospects in the technology of alcoholic cocktails;

- identification of the most promising sources of natural antioxidants for use in the technology of production of alcoholic cocktails; 
- determine the best modifications of alcoholic cocktails;

- to develop a prescription composition of alcoholic cocktails.

Object of study: characteristics and quality indicators of water-alcohol infusions from plant raw materials: organoleptic indicators (color, smell, taste); physicochemical parameters ( $\mathrm{pH}$ level, redox potential).

Subject of study: vodka with a volume fraction of ethyl alcohol $-40 \%$ (control); water-alcohol infusions from fruit raw materials: gooseberries, blueberries, cranberries, cherries, sweet cherries, strawberries, turf, grapes, plums; cognac $3 *$.

Research methods: redoxmetry - determination of antioxidant capacity of water-alcohol infusions of vegetable raw materials; $\mathrm{pH}$-metry; methods for determining organoleptic parameters.

Research methodology. The vegetable raw material was ground to a size of $3 \times 3 \mathrm{~mm}$, a portion of $4 \mathrm{~g}$ was placed in glass vials, $100 \mathrm{ml}$ of alcoholcontaining solvent with a volume fraction of alcohol of $40 \%$ was poured. The vials were closed with lids and placed in a dry air thermostat for 48 hours at a temperature of $40^{\circ} \mathrm{C}$. The resulting infusions were cooled to a temperature of $20^{\circ} \mathrm{C}$. Next, the infusions were filtered and studies were performed to determine the indicators of active acidity, which was measured on a $\mathrm{pH}$ meter in the mode of $\mathrm{pH}$ measurement with a combined glass electrode. The redox potential was measured in the potential measurement mode with a combined redoxmetric platinum electrode.

\section{The scientific novelty is:}

- determination of groups of infusions by antioxidant activity: infusions with low activity - 0 samples; infusions with medium activity - 0 samples; infusions with high activity -9 samples (100\%), among which the lowest value of $\mathrm{RE}=224.4 \mathrm{mV}$ have infusions of strawberry fruits and the most of sweet cherries fruits $(\mathrm{RE}=281.8 \mathrm{mV})$;

- the minimum theoretically expected value of redox potential of $\mathrm{RP}_{\min }$ for water-alcohol infusions of fruits, which has a value from $371.4 \mathrm{mV}$ (strawberry fruit), to $433.2 \mathrm{mV}$ (cherries fruit), and the actual measured redox potential of $\mathrm{RP}_{\mathrm{act}}$ - from $146.0 \mathrm{mV}$ (sweet cherries fruit) to $195.0 \mathrm{mV}$ (cranberry fruit);

- the minimum value of regenerative capacity (the energy of recovery $\mathrm{RE}$ ) was determined, which is equal to $-224.4 \mathrm{mV}$ and is characteristic of strawberry fruits, and the highest value of $281.8 \mathrm{mV}$ has a water-alcohol infusion of sweet cherries fruits;

- it was found that the $\mathrm{pH}$ level for water-alcohol infusions ranges from 3.78 (cherries fruit) to 4.81 (strawberry fruit), i.e. infusions have an acidic reaction;

- establishing the most promising samples of water-alcohol infusions of sweet cherries, cherries, gooseberries and plums, which showed the highest 
values of antioxidant capacity RE $242.0 \ldots 281.8 \mathrm{mV}$, received high organoleptic characteristics and can be recommended in the technology of alcoholic cocktails;

The socio-economic significance of the results is to create a semifinished product for products with improved consumer properties with water-alcohol infusions of fruit raw materials - sweet cherries, cherries, gooseberries or plums.

\section{Technology of blends}

One of the limiting stages of alcohol production is the process of preparation of appropriate high-quality blends. The existing technology of blends involves homogenization and distribution of flavored components in a bathed container by mechanical mixing with stirrers, or by conducting a closed circulation cycle according to the scheme: capacity - pump capacity. A significant disadvantage of these homogenization schemes is the duration of the process.

These methods of homogenization allow to obtain blends, the quality of which is provided by the regulatory documentation with tolerances. However, even the permissible deviation from the norm of such components as alcohol and sugar, leads to a decrease in the taste of the drink and, as a consequence, consumer properties.

One of the important areas of development of the food industry is to improve the taste, aroma of food, preservation (or supplementation) of the nutritional value of the final product. In most countries, functional, energy products containing biologically active substances of targeted action from natural raw materials are becoming widespread. The creation of a number of new products with the use of food additives (including extracts) for people of all ages and body conditions is aimed at maintaining and improving their health.

A large group of flavoring substances are plant products that also have biological value: vitamins, trace elements, carotene, natural acids and others. Many substances have medicinal properties, which provides their therapeutic and prophylactic effect in a variety of foods. Currently, more than 200 species of medicinal plants are known, of which about $65 \%$ are wild plants that can be wisely used in the food industry.

\section{Materials and methods}

Object of research: characteristics and quality indicators of water-alcohol infusions from plant raw materials: organoleptic indicators (color, smell, taste); physicochemical parameters ( $\mathrm{pH}$ level, redox potential).

Subject of research: water-alcohol mixture with a volume fraction of ethyl alcohol - 40\% (control); water-alcohol infusions from fruit raw materials: gooseberries, blueberries, cranberries, cherries, sweet cherries, strawberries, turf, grapes, plums; cognac $3 *$. 
The following basic raw materials were used to prepare infusions: rectified ethyl alcohol; prepared water; vegetable raw materials - in accordance with current regulations, which are allowed for use in the alcoholic beverage industry of Ukraine; filter cardboard.

The use of other raw materials and auxiliary materials is possible in accordance with current regulations, which are allowed for use by the central executive body in the field of health care of Ukraine.

Alcohol infusion (alcoholic beverage production) - a semi-finished product, which is prepared by infusion of vegetable raw materials (both aromatic and non-aromatic) in aqueous-alcoholic solution with a strength of $40 \%$ to $90 \%$.

Infusions must meet the requirements of regulatory documentation and must be manufactured in accordance with technological instructions and regulations, in compliance with state sanitary norms and rules, which are approved in accordance with the established procedure of the central executive body in the field of health of Ukraine.

\subsection{Methods of experimental research}

Vegetable raw materials were scraped with scissors to a size of approximately $3 \times 3 \mathrm{~mm}$, placed a sample of $10 \mathrm{~g}$ in glass vials of dark glass, poured $100 \mathrm{ml}$ of water-alcohol mixture with a volume fraction of $40 \%$ ethyl alcohol. The vials were capped and placed in a dry air thermostat for 48 hours at $40{ }^{\circ} \mathrm{C}$ to accelerate the infusion. The resulting infusions were cooled to room temperature.

The active $\mathrm{pH}$ index was measured on a $\mathrm{pH}$ meter with a combined glass electrode. The redox potential was measured on a $\mathrm{pH}$ meter of the mark, in the mode of measuring the potential, with a combined redoxmetric platinum electrode.

The total antioxidant activity of plant raw materials can be assessed using different methods, which differ in the type of oxidation source, oxidizing compounds and the method of its measurement. The best known are volumetric, photochemiluminescent, fluorescent methods, as well as the Folin-Ciocalteu method, the method of cyclic voltammetry, potentiometric method using a mediator system, a method based on the principle of indirect determination of the number of peroxils.

Most of these methods are usually based on reactions of interaction with long-standing free radicals. Such methods of assessing the total antioxidant activity have a number of features that limit their application, namely: the analysis is carried out in several stages over a long period of time, the analytical signal must be recorded using expensive spectrophotometric or fluorometric equipment, it is necessary to use expensive reagents. 
In addition, most methods are not able to determine the total in a complex mixture of plant origin antioxidants of different classes or multifunctional antioxidants. Modern methods give a wide range of results that cannot be used alone, and the results must be interpreted with caution. According to experts, there is an objective impossibility of the existence of not only a single method for assessing the antioxidant activity of compounds, but even the possibility of comparing the results obtained by different methods. As a result, each researcher has the opportunity to choose a ready-made, create a new or modify an already known method, due to their own goals and capabilities.

Based on these reasons, to assess the antioxidant properties of the obtained water-alcohol plant extracts, the method, based on the difference of redox potential in inactivated inorganic solutions and complex biochemical media.

The main criteria of this method were its clarity, simplicity, specificity, reproducibility of results and efficiency. A number of researchers also emphasize that method allows to determine the total antioxidant activity of liquid products, including in total in a complex mixture, and multifunctional antioxidants.

To evaluate the $\mathrm{pH}$ and redox potential (RP) of solutions, the following formula is valid:

$$
\mathrm{RP}_{\min }=660-60 \cdot \mathrm{pH}, \mathrm{mV}
$$

where $\mathrm{RP}_{\min }$ - the minimum theoretically expected value of the redox potential;

$\mathrm{pH}$ - the hydrogen index of the test solution.

The acquired values of $\mathrm{RP}_{\text {min }}$ are compared with actual measurements of $\mathrm{RP}_{\mathrm{act}}$ of solution. The shift of the redox potential towards the recovery values, as the recovery energy (RE), is determined by the formula:

$$
\mathrm{RE}=\mathrm{RP}_{\text {min }}-\mathrm{RP}_{\mathrm{act}}, \mathrm{mV}
$$

where RE - the energy of recovery (restorative capacity);

$\mathrm{RP}_{\mathrm{act}}$ - the actual measured redox potential of the solution.

The $\mathrm{pH}$ value is in the range from 1 to 14 and is determined by the quantitative ratio in the water of $\mathrm{H}^{+}$and $\mathrm{OH}^{-}$ions formed during the dissociation of water. If the content of free hydrogen ions $(\mathrm{pH}>7)$ in water is reduced in comparison with $\mathrm{OH}^{-}$ions, water will have an alkaline reaction, and at the increased content of $\mathrm{H}^{+}$ions $(\mathrm{pH}<7)-$ acidic. In perfectly pure distilled water, these ions will balance each other. In such cases, the water is neutral and $\mathrm{pH}-7$.

Redox potential (redox potential) is an important indicator of the biological activity of solutions. Characterizes the deviation from the ionic balance of free electrons in a liquid medium. 
The change in the concentration of free electrons leads to a change in its electron charge and, accordingly, in the redox potential. If the redox potential is positive, it indicates the oxidizing ability of the solution, and negative - the reducing. Thus, the magnitude of the redox potential allows us to estimate the energy of the processes, i.e. characterizes the activity of ions in redox reactions.

When redoxometry of the redox potential of the internal environment of a healthy person is less than zero, while the redox potential of drinking water from the city water supply network depending on the season, place of collection, water treatment system is always more than zero.

These differences in the redox potential of the internal environment of the human body and drinking water mean that the activity of electrons in the internal environment of the body is much higher than the activity of electrons in drinking water. In this case, the body undergoes the necessary change in the redox potential of drinking water due to the consumption of electrical energy of cell membranes, i.e. energy of the highest level, which is actually the end product of the biochemical chain of nutrient transformation. The amount of energy expended by the body to achieve the biological compatibility of water is proportional to its amount and the difference between the redox potential of water and the internal environment of the human body.

In addition to drinking water, people consume aqueous and aqueousalcoholic solutions, food products, the redox potential of which is positive. When such products enter the tissues of the body is the subtraction of electrons from cells and tissues, which are $80 \ldots 90 \%$ composed of water. As a result, the biological structures of the body are subject to oxidative destruction, the body wears out, ages, vital organs lose their function.

When aqueous solutions or foods with a negative redox potential close to the redox potential of the internal environment of the human body enter the body, the electrical energy of cell membranes is not spent on correcting the electron activity of these aqueous solutions or food, so the products are immediately absorbed, because they are biocompatible with this parameter.

If aqueous solutions or foods have a redox potential more negative than the redox potential of the body's internal environment, they feed it with this energy, which is used by cells as an energy reserve of antioxidant protection against adverse environmental influences.

Therefore, in order for the human body to make optimal use of wateralcohol solutions and food in metabolic processes, the values of redox potential must correspond to the values of redox potential of the internal environment of the body, or have more negative values. 


\section{Results and discussions}

\subsection{Experimental studies of water-alcohol infusions}

In the process of research, all herbal water-alcohol infusions are grouped by antioxidant activity: infusions with low activity (from 0 to $100 \mathrm{mV}$ ); infusions with medium activity (from 100 to $200 \mathrm{mV}$ ); infusions with high activity (from $200 \mathrm{mV}$ and above).

The object of the study was selected 9 samples of vegetable raw materials, which were used to make water-alcohol infusions and 2 samples with control (vodka, cognac $3 *$ ), which were evaluated by organoleptic (table 1) and physicochemical parameters (table 2).

The first sample is a water-alcohol mixture with a volume fraction of rectified ethyl alcohol of $40 \%$, which at $\mathrm{t}=19^{\circ} \mathrm{C}$ has the following parameters: $\mathrm{pH}$ level $-7.57, \mathrm{RP}_{\min }=205.8 \mathrm{mV}, \quad \mathrm{RP}_{\mathrm{act}}=64.0 \mathrm{mV}$, $\mathrm{RE}=141.8 \mathrm{mV}$. Organoleptic properties of the control sample: color colorless; aroma - alcohol; taste - moderately burning, empty.

The second sample is cognac $3^{*}$, which at $\mathrm{t}=20^{\circ} \mathrm{C}$ has the following parameters: $\mathrm{pH}$ level $-3.80, \mathrm{RP}_{\min }=432.0 \mathrm{mV}, \quad \mathrm{RP}_{\mathrm{act}}=170.0 \mathrm{mV}$, $\mathrm{RE}=262.0 \mathrm{mV}$. Organoleptic properties of the control sample: color - light amber; aroma - soft, alcoholic; taste - burning, cognac.

Table 1

\section{Organoleptic parameters of the studied samples}

\begin{tabular}{|c|l|l|l|l|c|}
\hline № & \multicolumn{1}{|c|}{$\begin{array}{c}\text { Name of raw } \\
\text { materials }\end{array}$} & \multicolumn{1}{|c|}{ Color } & \multicolumn{1}{|c|}{ Scent } & \multicolumn{1}{c|}{ Taste } & $\begin{array}{c}\text { General } \\
\text { assessment, } \\
\text { score }\end{array}$ \\
\hline 1 & Vodka (control) & colorless & spirituous & $\begin{array}{l}\text { Moderately } \\
\text { burning, empty }\end{array}$ & 9.57 \\
\hline 2 & Cognac $3 *$ control) & light amber & soft, alcoholic & $\begin{array}{l}\text { burning, } \\
\text { cognac }\end{array}$ & 8.98 \\
\hline 3 & $\begin{array}{l}\text { Infusion of } \\
\text { gooseberry }\end{array}$ & light pink & alcohol, fruit & burning, fruity & 9.56 \\
\hline 4 & Infusion of blueberry & light red & tart & saturated & 9.63 \\
\hline 5 & Infusion of cranberry & light red & fresh & bright & 9.58 \\
\hline 6 & Infusion of cherries & light red & spirituous & sweet and sour & 9.54 \\
\hline 7 & $\begin{array}{l}\text { Infusion of sweet } \\
\text { cherries }\end{array}$ & dark red & $\begin{array}{l}\text { bright, } \\
\text { alcoholic }\end{array}$ & $\begin{array}{l}\text { sweet, } \\
\text { aftertaste }\end{array}$ & 9.61 \\
\hline 8 & $\begin{array}{l}\text { Infusion of } \\
\text { strawberries }\end{array}$ & light pink & soft, strawberry & semi-sweet & 9.54 \\
\hline 9 & Infusion of turfgrass & light golden & saturated & tart & 9.62 \\
\hline 10 & Infusion of grapes & pink & spirituous & $\begin{array}{l}\text { soft, slightly } \\
\text { burning }\end{array}$ & 9.59 \\
\hline 11 & Infusion of plum & bright golden & soft, rich & $\begin{array}{l}\text { tart, slightly } \\
\text { burning }\end{array}$ & 9.65 \\
\hline
\end{tabular}


Table 2

Physicochemical parameters of the studied samples

\begin{tabular}{|c|l|c|c|c|c|}
\hline № & \multicolumn{1}{|c|}{$\begin{array}{c}\text { Name of raw } \\
\text { materials }\end{array}$} & $\begin{array}{c}\mathrm{pH} \text { level, } \\
\text { units } \mathrm{pH}\end{array}$ & $\mathrm{RP}_{\min }, \mathrm{mV}$ & $\mathrm{RP}_{\text {act }}, \mathrm{mV}$ & $\mathrm{RE}, \mathrm{mV}$ \\
\hline 1 & Vodka (control) & 7.57 & 205.8 & 64 & 141.8 \\
\hline 2 & Cognac 3* (control) & 3.80 & 432.0 & 170 & 262.0 \\
\hline 3 & $\begin{array}{l}\text { Infusion of } \\
\text { gooseberry }\end{array}$ & 3.81 & 431.4 & 185 & 246.4 \\
\hline 4 & Infusion of blueberry & 3.85 & 429.0 & 190 & 239.0 \\
\hline 5 & Infusion of cranberry & 3.95 & 423.0 & 195 & 228.0 \\
\hline 6 & Infusion of cherries & 3.78 & 433.2 & 161 & 272.2 \\
\hline 7 & $\begin{array}{l}\text { Infusion of sweet } \\
\text { cherries }\end{array}$ & 3.87 & 427.8 & 146 & 281.8 \\
\hline 8 & $\begin{array}{l}\text { Infusion of } \\
\text { strawberries }\end{array}$ & 4.81 & 371.4 & 147 & 224.4 \\
\hline 9 & Infusion of turfgrass & 4.19 & 408.6 & 184 & 224.6 \\
\hline 10 & Infusion of grapes & 4.34 & 399.6 & 162 & 237.6 \\
\hline 11 & Infusion of plum & 4.25 & 405.0 & 163 & 242.0 \\
\hline
\end{tabular}

The minimum theoretically expected value of $\mathrm{RP}_{\min }$ for water-alcohol infusions from fruits, which has a value from $371.4 \mathrm{mV}$ (strawberry fruit), to $433.2 \mathrm{mV}$ (cherries fruit), and the actual measured $\mathrm{RP}_{\text {act }}-$ from $146.0 \mathrm{mV}$ (sweet cherries fruit) up to $195.0 \mathrm{mV}$ (cranberry fruit). At the same time, the minimum value of regenerative capacity (RE) is equal to $-224.4 \mathrm{mV}$ and is typical for strawberry fruits, and the highest value of $281.8 \mathrm{mV}$ has a water-alcohol infusion of sweet cherries. The $\mathrm{pH}$ level for water-alcohol infusions ranges from 3.78 (cherries fruit) to 4.81 (strawberry fruit), i.e. infusions have an acidic reaction.

Groups of infusions by antioxidant activity were distinguished: infusions with low activity - 0 samples; infusions with medium activity - 0 samples; infusions with high activity - 9 samples (100\%), among which the lowest value of $\mathrm{RE}=224.4 \mathrm{mV}$ have infusions from strawberries and the most from sweet cherries $(\mathrm{RE}=281.8 \mathrm{mV})$.

The graphical dependence of physicochemical parameters of herbal infusions is shown in Fig. 1, the dependence of organoleptic parameters and their reduction energy (antioxidant capacity) is shown in Fig. 2.

Water-alcohol infusions of sweet cherries, cherries, gooseberries and plums showed the highest values of antioxidant capacity $\mathrm{RE}=242.0 \ldots 281.8$ $\mathrm{mV}$, received high organoleptic characteristics and can be recommended in the technology of alcoholic cocktails.

Four samples with the highest antioxidant properties (sweet cherries, cherries, gooseberries, plums) were used to improve the alcoholic cocktail «Riddle» according to the recipe № 983 by content, wt. \%: vermouth - 30; cognac - 30; aromatic liqueur - 15; lemon juice -8 ; canned fruits -8 ; food ice -9 . 


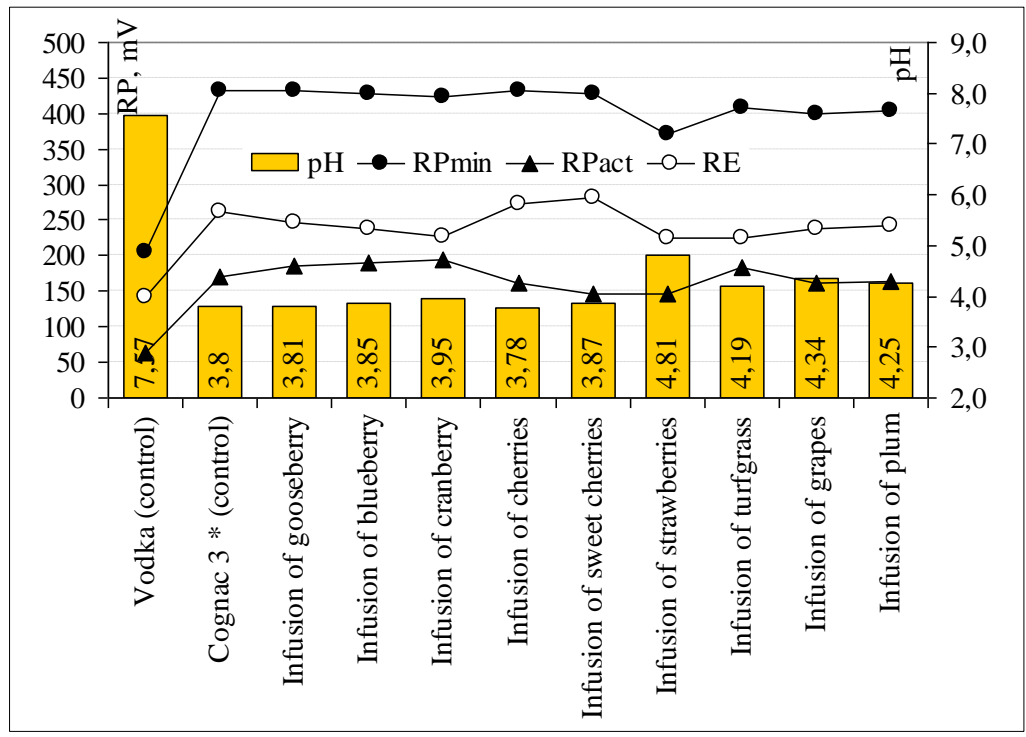

Fig. 1. Graphic dependence of physicochemical parameters of water-alcohol infusions from plant raw materials

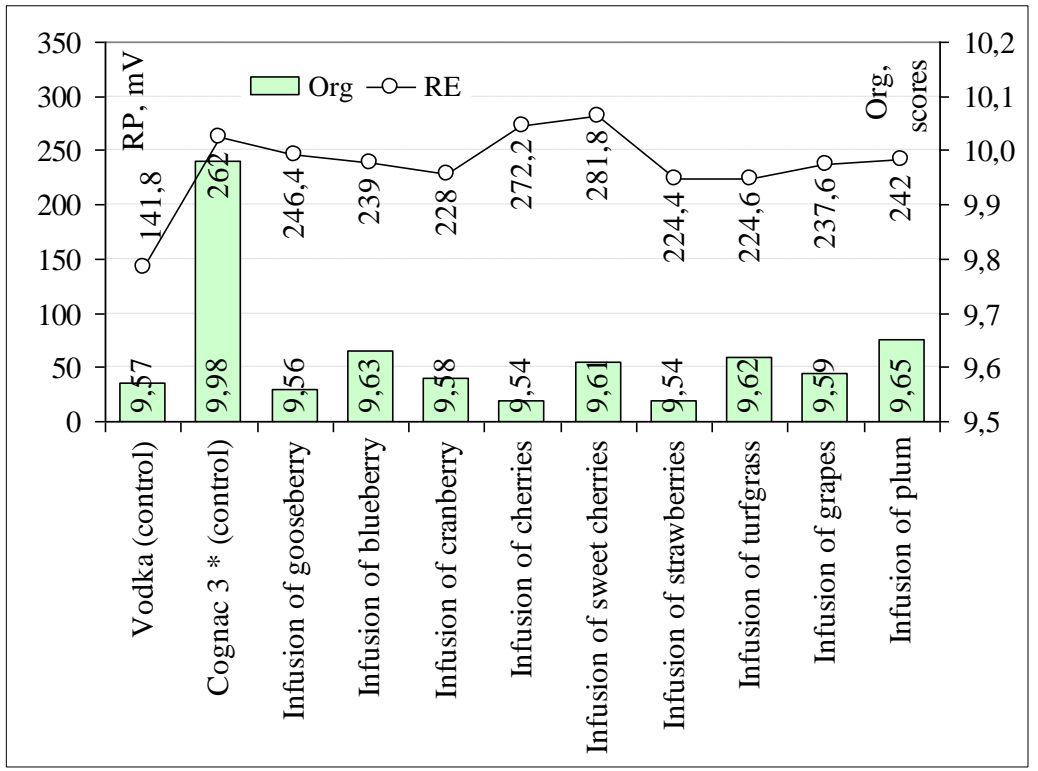

Fig. 2. Graphic dependence of organoleptic parameters and recovery energy of plant water-alcohol infusions 
The disadvantages of this composition of the ingredients of the cocktail are: the set value of the redox potential, which should change the speed and direction of the redox potential in the body; expected organoleptic parameters; increased cost.

\subsection{Improving the composition of alcoholic cocktails}

Improving the technology of alcoholic cocktails is due to the addition of herbal water-alcohol infusions. This allows to increase the redox properties of the product, enhances the immune system, improves metabolism, has a positive effect on the cardiovascular system, in addition, provides cocktails with improved consumer properties and reduces the cost of the finished product by replacing part of cognac, vermouth, cognac, vermouth on vegetable wateralcohol infusions.

An alcoholic cocktail was prepared according to the recipe № 983 with a different ratio of components, which differs from the classic recipe in that for blending the cocktail used additionally - water-alcohol infusion of sweet cherries, cherries, gooseberries or plums, the results of which are presented in table 3 .

Table 3

The ratio of the components of an alcoholic cocktail

\begin{tabular}{|c|c|c|c|c|c|c|c|c|}
\hline \multirow[b]{2}{*}{ № } & \multicolumn{7}{|c|}{ Prescription components, wt. \% } & \multirow[b]{2}{*}{ Conclusions } \\
\hline & 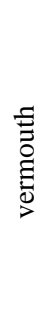 & $\begin{array}{l}\mathscr{Z} \\
\text { E. } \\
0 \\
0\end{array}$ & $\begin{array}{l}\Xi \\
\Xi \\
\Xi\end{array}$ & 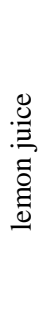 & 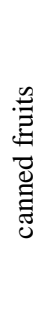 & $\begin{array}{l}.00 \\
.0 \\
0 \\
0\end{array}$ & 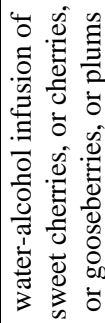 & \\
\hline 1 & 30 & 30 & 15 & 7 & 7 & 6 & 5 & $\begin{array}{l}\text { The composition of the recipe provides an } \\
\text { alcoholic cocktail with satisfactory } \\
\text { physicochemical and organoleptic } \\
\text { characteristics, but not sufficiently enriched } \\
\text { with biologically active substances }\end{array}$ \\
\hline 2 & 25 & 25 & 14 & 8 & 8 & 7 & 13 & \multirow{3}{*}{$\begin{array}{l}\text { The composition of the recipe provides an } \\
\text { alcoholic cocktail with good physicochemical } \\
\text { and organoleptic characteristics, as well as } \\
\text { sufficiently enriched with biologically active } \\
\text { substances }\end{array}$} \\
\hline 3 & 20 & 20 & 13 & 9 & 9 & 8 & 21 & \\
\hline 4 & 15 & 15 & 12 & 10 & 10 & 9 & 29 & \\
\hline 5 & 10 & 10 & 11 & 11 & 11 & 10 & 37 & $\begin{array}{l}\text { The composition of the recipe provides an } \\
\text { alcoholic cocktail with good physicochemical } \\
\text { parameters and biologically active substances, } \\
\text { but deteriorated organoleptic characteristics }\end{array}$ \\
\hline
\end{tabular}


The problem is solved by the fact that the alcoholic cocktail includes vermouth, cognac of Ukraine, liqueur, lemon juice, canned fruit, food ice, as well as vegetable water-alcohol infusion, in the ratio of components, by content, wt. \%: vermouth $-15 \ldots 25$; cognac $-15 \ldots 25$; liqueur $-12 \ldots 14$; lemon juice $-8 \ldots 10$; canned fruits $-8 \ldots 10$; food ice 7...9; water-alcohol infusion of sweet cherries, or cherries, or gooseberries, or plums - 13...29.

Therefore, the composition of the alcoholic cocktail is proposed due to the addition of vegetable water-alcohol infusion to the recipe, which increases the redox properties of the finished product, provides it with improved consumer properties and reduces the cost of the finished product.

\section{CONCLUSIONS}

We found that one of the promising ways to form consumer properties and expand the range of alcoholic beverages is the use of various compositions of ingredients, new types of food additives and biologically active substances. Such substances or their combinations are designed to improve the organoleptic properties of beverages, give them stable therapeutic and prophylactic properties - to promote human health (antioxidant, membrane-stabilizing effect, enhancement of redox reactions) and increase the body's protective functions against adverse factors and adverse factors. hormonal status of the body).

The creation of alcoholic products with low levels of toxicity allows the manufacturer to bring new types of products to market. It is these products that favorably distinguish the manufacturer's range from the range of competitors, creating a favorable image of the company, which cares about protecting consumers from the negative effects of alcohol through the use of the latest technologies.

\section{SUMMARY}

Our experimental studies show that all water-alcohol extracts of plant origin contain antioxidant systems. It was found that the value of the regenerative capacity of all studied extracts is positive and is in the range from 224.4 to $281.8 \mathrm{mV}$. There are three groups of plants as the antioxidant activity of the extracts.

Thus, the study of redox reactions that occur during the manufacture of aqueous-alcoholic extracts is important to ensure their stability and safety for consumption. It is necessary to further clarify the role of natural antioxidants of plant origin in these processes, to find ways to inhibit unwanted oxidative processes. 


\section{REFERENCES}

1. Herbal distillates: A new era of grape marc distillates with enriched antioxidant profile / V. Andreou at al. Food Chemistry. 2018. 253. P. 171-178. DOI 10.1016/j.foodchem.2018.01.162

2. Buglass A.J., Caven-Quantrill D.J. 16: Applications of natural ingredients in alcoholic drinks. Natural Food Additives, Ingredients and Flavourings. 2012. P. 358-416. DOI 10.1533/9780857095725.2.358

3. Chandrasekara A., Shahidi F. Herbal beverages: Bioactive compounds and their role in disease risk reduction - A review. Journal of Traditional and Complementary Medicine. 2018. 8 (4). P. 451-458. DOI 10.1016/j.jtcme.2017.08.006

4. Metabolic and antioxidant profiles of herbal infusions and decoctions / C. Fotakis at al. Food Chemistry. 2016. 211. P. 963-971. DOI 10.1016/j.foodchem.2016.05.124

5. Grunert K.G., Hieke S., Juhl H.J. Consumer wants and use of ingredient and nutrition information for alcoholic drinks: A cross-cultural study in six EU countries. Food Quality and Preference. 2018. 63. P. 107-118. DOI 10.1016/j.foodqual.2017.08.005

6. Halliwell B., Gutteridge J.M.C. The antioxidants of human extracellular fluids. Archives of Biochemistry and Biophysics. 1990. 280. P. 1-8. DOI 10.1016/0003-9861(90)90510-6

7. Teas and herbal infusions as sources of melatonin and other bioactive non-nutrient components / T. Herrera at al. LWT. 2018. 89. P. 65-73. DOI 10.1016/j.lwt.2017.10.031

8. Physicochemical and sensory profile of Beauregard sweet potato beer / B.V. Humia at al. Food Chemistry. 2020. 312. DOI 10.1016/j.foodchem.2019.126087

9. Iannitti T., Palmieri B. Antioxidant therapy effectiveness: an up to date. European Review for Medical and Pharmacological Sciences. 2009. 13. P. $245-278$.

10. Imark C., Kneubühl M., Bodmer S. Occurrence and activity of natural antioxidants in herbal spirits. Innovative Food Science \& Emerging Technologies. 2000. 1 (4). P. 239-243. DOI 10.1016/S1466-8564(00)00018-7

11. Fruit and herbal meads - Chemical composition and antioxidant properties / J. Kawa-Rygielska at al. Food Chemistry. 2019. 283. P. 19-27. DOI 10.1016/j.foodchem.2019.01.040

12. The effect of simulated gastro-intestinal conditions on the antioxidant activity of herbal preparations made from native Irish hawthorn / L. Keating at al. Journal of Herbal Medicine. 2014. 4 (3). P. 127-133. DOI 10.1016/j.hermed.2014.05.003

13. Improvement technologies of aqueous-alcoholic infusions for the production of syrups / O. Kuzmin at al. Ukrainian Journal of Food Science. 2016. 4 (2). P. 258-275. DOI 10.24263/2310-1008-2016-4-2-8 
14. Kuzmin O.V., Rudyi V.V. Prospects for the use of alcohol infusions in alcoholic beverage technologies for restaurants. Modern engineering research: topical problems, challenges and modernity : collective monograph. Riga : Izdevnieciba "Baltija Publishing", 2020. P. 211-230. DOI 10.30525/978-9934-588-47-1.9

15. Internal mechanisms for establishment of the equilibrium state of wateralcohol mixtures in vodka technology / O. Kuzmin at al. Ukrainian Food Journal. 2018.7 (4). P. 655-670. DOI: 10.24263/2304-974X-2017-6-1-10

16. Identification of equilibrium state of hydroxyl protons in vodkas by ${ }^{1}$ H NMR spectroscopy / O. Kuzmin at al. Ukrainian Food Journal. 2017. 6 (2). P. 314-336. DOI: 10.24263/2304-974X-2017-6-1-12

17. Naithani V., Nair S., Kakkar P. Decline in antioxidant capacity of Indian herbal teas during storage and its relation to phenolic content. Food Research International. 2006. 39 (2). P. 176-181. DOI 10.1016/j.foodres.2005.07.004

18. Antioxidant and antimicrobial activities of various leafy herbal teas / J. Oh at al. Food Control. 2013. 31 (2). P. 403-409. DOI 10.1016/j.foodcont.2012.10.021

19. Pyrzynska K., Sentkowska A. 5: Herbal Beverages as a Source of Antioxidant Phenolics. Natural Beverages. 2019. P. 125-142. DOI 10.1016/B978-0-12-816689-5.00005-5

20. Antioxidant Activity of Polyphenols Extracted From Hop Used in Craft Beer / J.C. Ruiz-Ruiz at al. Biotechnological Progress and Beverage Consumption. 2020. P. 283-310. DOI 10.1016/B978-0-12-816678-9.00009-6

21. Stern S.A., Terry-McElrath Y.M., Patrick M.E. Beverage-specific patterns of 5+ alcoholic drink consumption by young adults in the U.S. Addictive Behaviors. 2017. 65. P. 19-24. DOI 10.1016/j.addbeh.2016.09.010

\section{Information about the authors:} Kuzmin O. V., Candidate of Technical Sciences, Associate Professor of the Department of Technology of Restaurant and Ayurvedic Products of the National University of Food Technologies 68, Volodymyrska str., Kyiv, 01601, Ukraine

Mishurovskyi A. S.,

Student of the

National University of Food Technologies 68, Volodymyrska str., Kyiv, 01601, Ukraine 